\title{
O trabalho do dirigente de unidades de informação sob diferentes perspectivas administrativas
}

\author{
Simone de A.R. Branício
}

simonear@ffclrp.usp.br-Universidade de São Paulo

Claúdio M. Castro Filho

claudiomarcondes@ffclrp.usp.br-Universidadede São Paulo

O trabalho do dirigente de unidades de informação é discutido sob diferentes perspectivas administrativas, refletindo sobre novas formas de se entender o trabalho desse profissional à luz de abordagens que contemplam conceitos como gestão do aprendizado, competências e liderança. Em uma delas, as funções do administrador são definidas como planejar, organizar, dirigir e controlar, enquanto que outras evidenciam a avaliação das atividades rotineiras e a necessidade de uma visão integrada da unidade como forma de facilitar as tomadas de decisão.

Palavras-chave: Administração de unidades de informação; Função gerencial em bibliotecas; Teorias administrativas.

\section{The work of the information unit manager under different administration perspectives}

The work of the information unit manager is discussed under different administration perspectives (learning management, competences and leadership) as an attempt to understand the role of this professional. In one of the approaches, the function of the manager is defined as planning, organizing, directing and controlling. Others concentrate on the evaluation of regular activities and the need of an integrated view of the unit as a way to help in the decision making process. 
Keywords: Administration in information units; Library management; Administrative theories.

Recebido em 02.05.2007 Aceito em 01.10.2007

\section{Introdução}

O trabalho exercido pelos dirigentes ${ }^{1}$ nos diferentes tipos de instituição não é um tema desconhecido no meio acadêmico, mas as várias abordagens encontradas na literatura mostram que não há consenso entre os estudiosos sobre o que realmente estes indivíduos fazem em uma organização. Essa diversidade de visões pode ser atribuída primeiramente à metodologia utilizada nos estudos, uma vez que o pesquisador pode ser influenciado, mesmo que inconscientemente, pelos métodos escolhidos; pela natureza das organizações estudadas; e ainda por fatores ligados ao contexto do investigador, como o local de realização da pesquisa, o momento histórico do estudo e os objetivos específicos da pesquisa.

Embora para os profissionais da informação a função de executivo, dirigente ou qualquer outra denominação que englobe elementos como autonomia, poder e tomada de decisão, ainda não seja uma realidade constante na rotina de trabalho, muitas das atividades executadas exigem certo grau de comprometimento com a gestão da unidade de informação em que atuam.

É importante que se faça essas observações, pois o objetivo deste trabalho é apresentar os aspectos principais dessas abordagens e refletir sobre como esse profissional tem, ao longo do tempo, se comportado em relação às práticas gerenciais, à luz das teorias administrativas. Neste sentido, é usada a classificação de Escrivão Filho (1995), que apresenta três perspectivas para o entendimento do trabalho do executivo: as abordagens de Processo, Papéis e Diagnóstico. Finalizando o estudo dessas abordagens, são feitas algumas observações que dizem respeito a outros estudos que não estão enquadrados nestas categorias, mas que são igualmente significativos para as reflexões sobre o tema.

\section{Abordagens para o trabalho do executivo e da gerência em unidades de informação}

No final do século XIX e início do século XX, o aparecimento das grandes corporações tratou de evidenciar a figura do chefe, que desde 0 início da revolução industrial vinha se fortalecendo. Da mesma forma, as duas guerras mundiais contribuíram para que as organizações americanas (espelhos para o resto do mundo) se fortalecessem e ocupassem um espaço social mais visível. Os empresários, neste período, puderam

1As denominações gerente, chefe, dirigente, executivo e administrador possuem a mesma conotação no presente trabalho. 
trabalhar em um esforço conjunto com as forças armadas, o que contribuiu para que, depois das guerras, a estrutura e gerência das empresas se assemelhassem significativamente ao estilo militar (SAMPSON, 1997).

Sampson (1997), ao fazer um acompanhamento da função do gerente e do seu desenvolvimento e mudança de comportamento desde as primeiras décadas do século XX até meados dos anos 90 , nota a submissão e omissão desses gerentes em relação a seus superiores, como também uma crescente insegurança em relação à manutenção do emprego ao longo do tempo. Este sentimento tornou-se mais forte a partir da década de 80 , quando o movimento de horizontalização das empresas foi destaque entre as técnicas administrativas. Para Sampson (1997), o gerente atual possui algumas características distintas: oportunista, flexível, criativo e empreendedor.

Especificamente em relação ao profissional da informação no Brasil, uma pesquisa realizada na década de 90 (TARAPANOFF, 1997) já apontava para um crescente envolvimento do bibliotecário em atividades administrativas, mas mostrava que o perfil do profissional ainda estava fortemente relacionado às atividades mais tradicionais da área. Nesse mesmo contexto, mas atentando-se ao estilo gerencial dos administradores de bibliotecas universitárias, outro estudo (FUNARO, 1997) assinalava a falta de treinamento e/ou inadequação da preparação formal recebida pelos bibliotecários para a função de gerência. Observando pesquisas como estas, é possível, então, depreender que as atividades mais voltadas para os aspectos funcionais e operacionais das unidades de informação, tais como a geração, uso, organização e disseminação dos diversos produtos informacionais, ainda ocupam a maior parte da agenda dos profissionais da área, em detrimento das atividades chamadas "gerenciais", as quais são tratadas nos próximos tópicos.

\subsection{A abordagem de Processo}

A primeira das abordagens analisadas neste estudo diz respeito à Escola do Processo Administrativo, que teve origem no trabalho de Henry Fayol e foi responsável por definir a administração pelos atos de planejar, organizar, dirigir e controlar. Conseqüentemente, estas funções também acabaram sendo usadas para definir o papel do dirigente na empresa (MAXIMIANO, 2004).

Gulick (1973) usa uma sigla para reforçar essa idéia sobre as atividades desenvolvidas por um administrador - POSDCORB (do inglês planning, organizing, staffing, directing, co-ordinationing, reporting e budgesting):

a) Planning: planejar o que deve ser feito e os métodos de se realizar;

b) Organizing: estabelecer uma estrutura formal de autoridade; 
c) Staffing: contratar e treinar funcionários, além de manter condições favoráveis de trabalho;

d) Directing: tomar decisões e incorporá-las em instruções e ordens gerais e específicas;

e) Co-ordinationg: interligar as várias partes do trabalho;

f) Reporting: informar seus subordinados dos acontecimentos assim como se manter informado;

g) Budgesting: monitorar o orçamento através de planejamento e controle fiscal e contábil.

Outra importante contribuição para esta abordagem vem da Administração Científica, inaugurada por Frederick Winslow Taylor no início do século passado. Taylor era favorável à divisão das tarefas, e buscava a eficiência e eficácia do processo produtivo através da instituição de padrões e normas, como forma de sistematizar o trabalho. Essa "cientificidade" na maneira de se organizar o trabalho deu aos gerentes maior poder e legitimidade e, assim, eles puderam se respaldar no gerenciamento científico quando confrontados por regras arbitrárias e ilógicas dos empresários (SAMPSON, 1997).

Ao incorporar esse pensamento, a figura dos gerentes passa a ser a de indivíduos altamente controladores e preocupados em moldar os funcionários aos valores da empresa. Inicia-se daí as discrepâncias entre as funções operacionais e as de gerência, das quais resulta uma relação desigual, com comandantes de um lado e subordinados de outro. $O$ único ponto em comum é que todos acabam por perder a individualidade e se submetem à lógica organizacional: racional e voltada unicamente para a realização das tarefas.

A visão dos processualistas sobre o trabalho do executivo trouxe 0 planejamento como carro-chefe das atividades gerenciais. Segundo Mintzberg (1994), o problema é que esse planejamento representa um estilo gerencial baseado no cálculo e não no comprometimento. Enquanto gerentes comprometidos buscam engajar as pessoas na mesma "empreitada", os gerentes que possuem o estilo calculista se fixam no que deve ser feito e em "como chegar lá", sem se preocupar com as opiniões dos outros membros do grupo.

O plano, enquanto ferramental de destaque neste estilo, visava coordenar e integrar as várias áreas da empresa, beneficiando-se da existência dos vários níveis hierárquicos da "era pré-horizontalização" para que sua eficácia não fosse questionada; o que garantiu por muito tempo a aceitação deste instrumento por parte dos administradores.

A abordagem dos processualistas está presente na literatura das Ciências da Informação em trabalhos como os de Barbalho e Beraquet (1995) e os de Almeida (2005), nos quais o planejamento é tratado no contexto de unidades de informação. Enquanto que na área administrativa e econômica o POSDCORB são instrumentos fundamentais 
e possíveis de avaliação, na área da biblioteconomia e ciência da informação os primeiros passos ainda são dados nessa direção. Com a automação, esses passos se ampliaram a partir da revolução de produtos e serviços, o que gerou a necessidade de mudanças por parte do bibliotecário executivo, obrigado a rever seu perfil como administrador.

Barbalho e Beraquet (1995) destacam as funções gerenciais como sendo aquelas que se relacionam às atividades que mantêm as unidades funcionando de forma satisfatória, a saber: o planejamento, relacionado ao estabelecimento de metas e formas de atingi-las; a organização, voltada para as decisões sobre divisão do trabalho; o desempenho, relacionado à execução do trabalho em si; o controle, voltado para assegurar o alinhamento entre o trabalho que está sendo executado e o planejado; e a revisão, voltada para a análise e para o resumo do que foi feito.

O trabalho principal do profissional da informação em sua função de planejador consiste, de acordo com Almeida (2005), em interpretar a missão institucional e estabelecer objetivos, metas, políticas e diretrizes, procedimentos e regras para o serviço de informação. Assim, por exemplo, se for em relação ao desenvolvimento de um produto (físico ou conceitual), esse profissional terá a incumbência de torná-lo adequado às necessidades de sua clientela, tomando para si a responsabilidade de dirigir esse processo desde o seu planejamento até a avaliação do resultado final e possíveis redirecionamentos demandados por essa avaliação. No caso de um evento ou tarefa, a função desse dirigente poderá ser a de tornar a unidade de informação participativa em relação a seu público, além de elaborar ações em conjunto com outras unidades da organização a que pertence. No que se refere aos planos, a elaboração de políticas, os procedimentos e normas de acordo com a missão da unidade, juntamente com os cronogramas e orçamentos de projetos, refletem um pouco mais sobre o que é o papel do administrador no âmbito dos serviços informacionais segundo essa abordagem.

Em consonância com esta abordagem, pode-se dizer então que o dirigente da unidade de informação atua como uma figura essencial nos processos de desenvolvimento de coleções, treinamento de funcionários e usuários, avaliação de coleções, divisão de tarefas, entre outros. No entanto, sua atuação principal relaciona-se às tomadas de decisão, o que exige uma dimensão de competências intelectuais de um profissional que, segundo Castro Filho e Vergueiro (2004), deve ser versátil, flexível, dinâmico e com um perfil de empreendedor, preocupando-se também com o seu desenvolvimento profissional.

\subsection{A abordagem dos Papéis}

Navegando contra a corrente processual, encontramos alguns estudiosos que procuraram obter respostas mais concretas para 0 trabalho do administrador. Notadamente, John Kotter e Henry Mintzberg são alguns desses pesquisadores que criticam Fayol e seus seguidores por sintetizarem de maneira abstrata o trabalho dos administradores em 
planejar, organizar, dirigir e controlar. Para Kotter e Mintzberg, o uso da observação sistemática das atividades diárias é uma forma mais eficiente de descrever o que os executivos fazem na prática.

As constatações a que chegou Mintzberg (1986) trazem contribuições significativas para o entendimento do tema, pois derrubam vários mitos arraigados na concepção de atividade a que se dedica um administrador, como o mito que considera o administrador sistemático, planejador e reflexivo. Acreditar que as informações são obtidas através de um sistema formal e que as atividades rotineiras não fazem parte do trabalho do executivo são mitos também quebrados por essas pesquisas. Mintzberg coloca que o trabalho do executivo é caracterizado basicamente pela fragmentação e brevidade das atividades desenvolvidas, e pela comunicação verbal; uma vez que esse administrador não tem controle sobre seu tempo, executa atividades descontínuas, participa de compromissos rotineiros como eventos sociais, trabalha voltado para a ação e não para a reflexão, além de preferir a mídia verbal ao invés de cartas e relatórios. Fundamentado nessa percepção, o autor define dez papéis para o cargo de administrador, os quais são os responsáveis pela caracterização nesta segunda abordagem. Apesar de serem considerados inseparáveis, e mesmo reconhecendo que cada executivo atribui um peso diferente para cada um, esses papéis podem ser divididos nas seguintes categorias:

a) Papéis interpessoais:

- Imagem do chefe: o executivo desempenha algumas obrigações de natureza cerimonial.

- Líder: é responsável pelo trabalho de todos os funcionários de sua unidade.

- Contato: mantém relações fora de sua cadeia vertical de comando

b) Papéis informacionais:

- Monitor: está alerta ao ambiente a fim de obter informações.

- Disseminador: transmite as informações obtidas aos seus subordinados.

- Porta-voz: envia algumas de suas informações a pessoas externas à sua unidade.

c) Papéis decisionais:

- Empreendedor: procura melhorar sua unidade, adaptando-a as mudanças do ambiente.

- Manipulador de distúrbios: responde involuntariamente às pressões.

- Alocador de recursos: decide sobre quem obterá o quê na sua unidade. 
- Negociador: é responsável por negociações externas e internas.

Contemporâneo de Mintzberg e focando sua pesquisa nas pequenas e médias empresas brasileiras, Hélio J. Teixeira é outro estudioso que procura obter a resposta sobre o que faz os administradores, usando a observação estruturada das atividades cotidianas. Entre outras coisas, os resultados de sua pesquisa apontam para a insuficiência dos controles gerenciais e para o treinamento incompleto dos subordinados como dois aspectos de trabalho que impedem um maior aproveitamento do tempo pelos dirigentes e impõem a necessidade de mais contatos e supervisão dos trabalhos (TEIXEIRA, 1982).

Já Kotter (1986), apesar de encontrar basicamente as mesmas características que Mintzberg encontrou no trabalho diário do executivo, demonstra em suas conclusões maior cuidado e percepção dessa realidade. Para o autor, a natureza do trabalho requer que o executivo descubra meios que melhorem o seu desempenho, considerando sua dependência de um grande número de pessoas e a diversidade e volume de informações potencialmente relevantes com as quais terá que lidar. São apresentados, então, dois elementos que podem ajudá-lo no alcance dessa eficiência: a agenda de trabalho e a rede de relacionamentos.

A agenda configura-se em um planejamento informal, no qual o administrador estabelece metas, prioridades e objetivos que não estão explicitados no planejamento formal da organização, e onde se pode encontrar, entre outras coisas, dados financeiros, organizacionais e de mercado. A construção dessa agenda dá-se principalmente nos primeiros seis meses de um novo emprego, e sua atualização é constante no decorrer do tempo, mas com menor esforço despendido. Simultaneamente ao estabelecimento de sua agenda, o administrador se preocupa em construir sua rede de relacionamentos visando conseguir a cooperação, não só de seus subordinados, mas de todas as pessoas necessárias para o cumprimento de sua agenda, como colegas de gerência, seus chefes e pessoas de fora da organização (KOTTER, 1986).

Um ponto a ser destacado no trabalho de Kotter é que, ao contrário de Mintzberg, ele não considera o tempo gasto com contatos e a comunicação informal como prejudiciais ao trabalho do executivo, uma vez que isso pode garantir mais eficiência no uso e na manutenção da rede de relacionamentos, como também na implementação da agenda.

Quanto aos profissionais da informação, e observando os papéis interpessoais a que Mintzberg (1986) se refere, o dirigente da unidade de informação deve se apresentar como uma figura que traduz de forma convincente os objetivos e a missão da organização. Que a imagem de chefe seja a de um representante autêntico da unidade de informação, um "relações-públicas" que vai divulgar os produtos e serviços a seus clientes e a todos os outros interessados; ele deve também exercer paralelamente o papel de líder, pois, de alguma forma, tem que transmitir segurança para seus subordinados e ter uma certa influência com os clientes, fornecedores e demais funcionários da instituição. Ainda no aspecto 
interpessoal, outro papel igualmente importante a ser desempenhado é o de contato, ou seja, o de elo de ligação de sua unidade com outras. Nesse caso, esse profissional deve manter com seus pares uma boa relação, que permita o intercâmbio de recursos e informações.

Quanto aos papéis informacionais, esse dirigente se ocupa de fazerse presente no acompanhamento do fluxo de informação que permeia as atividades das quais é responsável. Neste sentido, receber informações externas, disseminá-las internamente e repassar outras informações para o ambiente externo são funções intrínsecas ao seu cargo. No papel de monitor, procura recuperar a informação externa e internalizá-la de forma a entender o impacto que essa informação tem no dia-a-dia de sua unidade. Como disseminador, seu papel é o de trabalhar ativamente para que sua equipe esteja sempre ciente das informações a que ele teve acesso e que, direta ou indiretamente, afetam o trabalho de cada um, ou que podem servir de inspiração para a melhoria da qualidade dos serviços oferecidos. Como porta-voz, age na seleção e disseminação de informações de sua unidade para um público mais amplo, fora de seu ambiente micro, seja este o ambiente da organização da qual sua unidade faz parte ou, ainda, o macro ambiente externo.

Já os papéis decisionais envolvem tomadas de decisão relacionadas a parcerias, negociações com fornecedores, empreendimentos, entre outras coisas. Como empreendedor, o dirigente busca, por exemplo, ampliar produtos e serviços conforme as necessidades apresentadas pela clientela e dar impulso às iniciativas de mudanças que possam melhorar o desempenho de seus funcionários e de toda a unidade de informação. Sendo um controlador de distúrbios, esse profissional tem que estar atento para amenizar crises que surjam e responder aos conflitos de maneira equilibrada, para que a unidade de informação continue a prestar um serviço de excelência, independentemente dos problemas a que está sujeita. Como alocador de recursos, é preciso que tenha competência para, entre outras coisas, administrar o seu tempo, 0 de seus funcionários, programar o seu trabalho e o alheio e determinar quais decisões terceiros podem tomar. Ainda entre os papéis decisionais, e na figura de negociador, precisa liderar as discussões com o poder superior da organização, bem como com seus clientes e fornecedores.

\subsection{A abordagem do Diagnóstico}

Para a apresentação dessa abordagem é usado o trabalho de Nadler e Tushman (1994), que adotam a premissa de que o comportamento organizacional deve ser modelado e bem administrado. Um dos instrumentos para influenciar os padrões de comportamento é o Projeto da Organização, denominado no estudo dos autores Arquitetura das Organizações. O conceito que envolve essa arquitetura está estreitamente ligado às decisões tomadas pelos administradores e, segundo Nadler e Tushman (1994) está submetido a duas perspectivas: 
- A perspectiva de desempenho estratégia/tarefa, que diz respeito a como a arquitetura permitirá que a organização execute seu trabalho;

- A perspectiva social/cultural, que busca saber como a arquitetura se harmonizará com aqueles que trabalham na organização.

O modelo de sistema aberto (aquele que interage com o ambiente) é usado para embasar as discussões dos autores, ao argumentarem que algumas das características desse modelo podem ser encontradas também nas organizações, como a interdependência interna, a capacidade de feedback e de se equilibrar, a equifinalidade e a adaptação às mudanças do ambiente. A contribuição de Nadler e Tushman (1994) está na proposição de um modelo próprio - o Modelo de Congruência do Comportamento Organizacional - que se mostra mais específico do que os sistemas abertos básicos. Como em qualquer outro modelo sistêmico, há a entrada do insumo, o processo de transformação e o produto resultante deste processo; mas o diferencial está na aceitação da congruência como medida de adequação entre pares dos seguintes componentes organizacionais:

a) Trabalho: a atividade básica a que a organização se dedica;

b) Pessoal: aqueles que realizam as tarefas;

c) Disposições organizacionais formais: estrutura e procedimentos que permitem a consistência entre as tarefas e a estratégia;

d) Organização informal: estrutura e procedimentos que surgem enquanto a organização opera.

A hipótese básica do modelo de congruência é em igualdade de condições, quanto maior o grau total de congruência entre os vários componentes, mais eficiente será a organização, definindo-se a eficiência como o grau em que o produto organizacional real é semelhante ao produto esperado ou planejado, tal como especificado pela estratégia (NADLER; TUSHMAN, 1994, p.39).

Com o modelo em mente, o executivo pode fazer um "mapeamento" da organização, enxergando muito além do que outras abordagens discutidas anteriormente. A abordagem do diagnóstico possibilita ao administrador entender o funcionamento da organização sob um ponto de vista comportamental, considerando aspectos que foram ignorados pelos processualistas, como a importância de se saber as necessidades e preferências das pessoas que estão envolvidas nas atividades e a relevância da organização informal. Esta abordagem parece oferecer também ao administrador uma visão mais abrangente de seu trabalho em comparação ao foco empírico da abordagem dos papéis, pois enquanto esta última ressente-se da falta de um planejamento mais formal das atividades rotineiras, na primeira é possível ver o administrador na posição de um arquiteto que aproveita as oportunidades da organização informal para definir suas estratégias e alcançar seus objetivos. 
Assim, o dirigente, visto pela abordagem do diagnóstico, tende a olhar para a estrutura da unidade a que pertence com uma percepção mais sistêmica da prática gerencial, verificando se esta estrutura corresponde às expectativas da macro-estrutura organizacional da empresa. Buscando a congruência dos diversos elementos que compõem a unidade de informação (denominados por Nadler e Tushman pessoal, organização formal, organização informal e estrutura), procura verificar, por exemplo, se as pessoas têm clareza de seus papéis, se conhecem os canais de comunicação para a condução de assuntos específicos e se têm comprometimento com a estrutura e com o trabalho. Ainda, observando 0 componente comportamental, procura entender como as relações informais interferem no trabalho do dia-a-dia do grupo através de aspectos como confiança, carinho, comunicação e compromisso.

Também 0 entendimento e 0 uso de novas tecnologias são importantes nessa abordagem. Borges (2004) destaca que o profissional da informação deve ser capaz de utilizar novos processos e instrumentos tecnológicos, como também de estar inserido na sociedade da informação e do conhecimento, a qual faz uso intensivo e em larga escala do computador para processamento de dados, redes de informação e comunicação e processos produtivos.

Todas essas preocupações de cunho gerencial levam o administrador a compreender as conexões que se estabelecem no interior de sua unidade de informação, seja no nível individual, de grupo, ou da organização como um todo. Para o dirigente de uma unidade de informação, analisar o trabalho do executivo sob o ponto de vista da estrutura organizacional parece ser um modo sensato de não cair nas armadilhas das generalizações.

\section{Outras abordagens}

Embora o objetivo do presente trabalho seja o de estudar as três abordagens já discutidas, ainda é cabível olhar para alguns estudiosos que possuem outras visões sobre as funções gerenciais.

Drucker (1989) deixa claro que as funções do administrador sofrem variações de acordo com o tamanho da empresa. Classificando-as em quatro estágios (pequena, média, grande e muito grande), Drucker usa como critério para distingui-las a atuação dos níveis administrativos, e não outros critérios preferidos por outros autores como o número de funcionários da organização.

Nessa visão, uma empresa pequena é aquela onde se pode encontrar um nível administrativo entre funcionários e o chefe, tornando-a algo além de negócio pessoal. Dois aspectos distinguem a média da pequena empresa: o trabalho administrativo deve ser em tempo integral e os objetivos globais da empresa não são estabelecidos exclusivamente pelo dirigente da empresa, pois este passa a sentir a necessidade de uma equipe dirigente. $O$ "salto" para a empresa se tornar grande é vislumbrado quando uma das duas funções que o cargo de cúpula exige não consegue ser mais cumprida por uma só pessoa, ou seja, a fixação de objetivos 
gerais ou o cumprimento das obrigações executivas passam a ser desempenhados por uma equipe. Já na empresa muito grande, essas duas funções são executadas em equipe, além dos problemas de relacionamento entre as gerências de cúpula e operacional começarem a exigir mais atenção da alta administração (DRUCKER, 1989).

Neste sentido, as considerações de Drucker oferecem mais uma perspectiva para se entender a função gerencial no âmbito das unidades de informação. Na pequena empresa, a unidade de informação está ligada diretamente ao executivo principal, sendo as negociações mais diretas e as decisões encaminhadas de forma mais rápida e interativa. Na média empresa, devido ao aumento de níveis hierárquicos, esse acesso direto com a alta gerência é prejudicado. Dessa forma, profissionais com perfil de negociador mais acentuado conseguem encaminhar as necessidades e sugestões da unidade de informação de modo mais eficiente. Na grande empresa, a atuação do dirigente da unidade de informação deve ser direcionada ao trabalho em equipe. Esse profissional precisa também se inserir em equipes de liderança da organização para que possa interagir com outros dirigentes e, dessa forma, ressaltar o trabalho da unidade dentro da organização.

Finalmente, uma das mais recentes contribuições ao estudo do tema aparece no trabalho de Senge (1990), no qual é apresentada a organização de aprendizagem como sendo aquele tipo de organização onde as pessoas estão sempre aprendendo e são responsáveis por seu aprendizado. No que diz respeito à administração, o conceito de liderança da visão tradicional é suplantada, pois se pressupõe que as pessoas não têm iniciativa nem objetivos pessoais, além de se mostrarem impotentes. $\mathrm{Na}$ organização de aprendizagem, as pessoas são ativas e aprendem a enxergar o todo, a interferir e fazer parte das mudanças organizacionais. O dirigente neste contexto adquire três funções: projetista, guia e professor.

- O dirigente como projetista tem a função de capacitar os outros para trabalharem por si próprios. Ele não espera o problema aparecer para ser resolvido mas, ao contrário, antecipa-se dissolvendo o problema.

- O dirigente como guia enxerga seu objetivo pessoal como parte de um objetivo maior.

- O dirigente como professor ajuda a mostrar aos outros que a visão da realidade é um recurso de criação e não uma fonte de limitação.

A impressão deixada por este trabalho é que, para ser um líder na organização de aprendizagem, precisa-se de tempo e identificação com a empresa, além de certo nível de lealdade organizacional - elementos que hoje não são tão expressivos nas organizações. Seria esse modelo tão independente da figura do líder a ponto de se estabelecer sem a sua presença intensiva? A resposta pode estar no fato da organização de aprendizagem ainda figurar como um modelo muito distante das teorias administrativas, mas existem estudiosos lidando com essa questão e 
reforçando a necessidade de se estabelecer canais de comunicação entre dirigentes e subordinados, respaldados em um relacionamento de confiança. Há uma correlação positiva entre os gerentes que buscam conduzir seu trabalho pensando na melhoria das atividades de todos e o grau de confiança da equipe nesse gerente, como também na própria organização. Esse tipo de líder "servidor" procura se comunicar claramente com seus subordinados ou parceiros e, assim, há trocas que beneficiam toda a organização. As práticas executadas por esses líderes influenciam a forma como a equipe lida frente aos desafios organizacionais, sendo toda a cultura organizacional moldada de acordo com as suas ações. (JOSEPH; WINSTON, 2005).

Alinhado a essa abordagem que foca o aprendizado de todo o grupo na organização, está o conceito de empowerment, que tem como objetivo transmitir responsabilidades e recursos a fim de obter 0 potencial intelectual das pessoas; de modo que possam mostrar liderança e competências individuais e, ao mesmo tempo, ajudá-las a enfrentar os desafios de toda empresa. Figuram entre os mais importantes princípios do empowerment:

a) Dar às pessoas plena autoridade e responsabilidade, independência e autonomia em suas tarefas e recursos;

b) Permitir que as pessoas tomem decisões a respeito de seu trabalho;

c) Construir relacionamentos entre as pessoas;

d) Mover a informação em todos os níveis. (CHIAVENATTO, 1999).

Pode-se dizer que nesta perspectiva de trabalho a aplicação do empowerment nas unidades de informação vem definir como requisito primordial o trabalho em equipe, no qual redes colaborativas destacam-se na produção e disseminação da informação.

\section{Conclusões}

Sendo o trabalho do profissional da informação, sob a perspectiva gerencial, o ponto central das discussões deste estudo, procurou-se destacar as atividades mais relevantes dos dirigentes das unidades de informação, correlacionando-as com algumas abordagens das teorias administrativas.

Dessa forma, destacaram-se elementos indispensáveis para a execução do trabalho de um dirigente como a ação colaborativa, a aprendizagem e atuação em grupo, a liderança participativa e o planejamento coordenado com a equipe. É sabido que o campo de atuação do profissional da informação é vasto e inserido em diversos ambientes da sociedade e, por isso, pode ser difícil ao dirigente de uma unidade de informação possuir diferentes atributos que atendam a todas as demandas do mercado profissional. Contudo, esses elementos apresentados no estudo não podem ser tratados de forma irrelevante por nenhum profissional que queira trabalhar em nível gerencial nas unidades 
de informação, sendo elas de pequeno, médio ou grande porte, privadas ou públicas.

Os estudos que buscam explicitar o trabalho dos executivos ainda são incipientes na área das Ciências da Informação, embora se saiba que atividades de cunho gerencial são muitas vezes praticadas de maneira inconsciente e sem coordenação por parte de alguns profissionais envolvidos quase que completamente com as tarefas operacionais e técnicas. É neste sentido que este estudo procura contribuir na área, destacando abordagens administrativas fundamentais para 0 desenvolvimento de qualquer unidade de informação.

Todas as abordagens discutidas neste trabalho apresentam pontos relevantes que, de alguma forma, trazem uma contribuição para o entendimento do assunto; embora se perceba que todas sejam parciais em suas análises e nem todas possam ser consideradas em qualquer tipo de unidade de informação, devendo-se respeitar as especificidades de cada uma. Se por um lado encontram-se estudiosos preocupados com o planejamento das atividades gerenciais, a utilização otimizada do tempo do gerente e o uso criativo das oportunidades de escolha administrativa; por outro lado vê-se aqueles que se dedicam a oferecer modelos mais sistêmicos e comportamentais. Talvez unindo todas essas preocupações seja possível chegar a uma perspectiva mais abrangente para se descrever a função administrativa e a do próprio dirigente de organizações voltadas para administração da informação.

\section{Referências}

ALMEIDA, M. C. B. Planejamento de bibliotecas e serviços de informação. Brasília: Briquet de Lemos, 2005.

BARBALHO, C. R. S.; BERAQUET, V. S. M. Planejamento estratégico para unidades de informação. São Paulo: Polis/APB, 1995.

BORGES, M. A. G. O profissional da informação: somatório de formações, competências e habilidades. In: BAPTISTA, S. G.; MUELLER, S. P. M. (Org.). Profissional da Informação: o espaço de trabalho. Brasília: Thesaurus, 2004. p. 55-59.

CASTRO FILHO, C. M.; VERGUEIRO, W. Gestão de pessoas em bibliotecas universitárias sob a ótica das teorias da qualidade: reflexões sobre a realidade brasileira. In: SEMINÁRIO NACIONAL DE BIBLIOTECAS UNIVERSITÁRIAS, 13., 2004, Natal. Anais... Natal: SNBU, 2004. v. 1.

CHIAVENATTO, A. Gestão de pessoas: o novo papel dos recursos humanos nas organizações. Rio de Janeiro: Elsevier, 1999.

DRUCKER, P. Prática de administração de empresa. São Paulo: Pioneira, 1989.

ESCRIVÃO FILHO, E. A natureza do trabalho do executivo: uma investigação sobre as atividades racionalizadoras do responsável pelo 
processo produtivo de empresas de médio porte. 1995. Tese (Doutorado) - Universidade Federal de Santa Catarina - UFSC, Florianópolis, 1995.

FUNARO, V. M. B. O. Estilo gerencial dos administradores de bibliotecas: o caso da Universidade de São Paulo. 1997. Dissertação (Mestrado) Faculdade de Biblioteconomia da PUCCAMP, Campinas, 1997.

GULICK, L. Papers on the science administration. New York: M. Kelly, 1973.

JOSEPH, E. E.; WINSTON, B. E. A correlation of servant leadership, leader trust, and organizational trust. Leadership \& Organizational Development Journal, v. 6, n. 1, p. 06-22, 2005.

KOTTER, J. P. What effective general managers really do. Harvard Business Review, v. 60, n. 6, p. 156-167, Nov./Dec.1986.

MAXIMIANO, A. C. A. Teoria geral da administração: da revolução urbana à revolução digital. São Paulo: Atlas, 2004.

MINTZBERG, H. Trabalho do executivo: o folclore e o fato. São Paulo: Nova Cultural, 1986.

. The fall and rise of strategic planning. Harvard Bussiness Review, v. 73, p. 107-114, Jan./Feb. 1994.

NADLER, D. A.; TUSHMAN, M. L. Arquitetura organizacional. Rio de Janeiro: Campus, 1994.

SAMPSON, A. O homem da companhia. São Paulo: Companhia das Letras, 1997.

SENGE, P. A nova função do dirigente. In: A quinta disciplina. São Paulo: Best Seller, 1990. p. 299-311.

TARAPANOFF, K. Perfil do profissional da informação no Brasil. Brasília: IEL/DF, 1997.

TEIXEIRA, H. J. O trabalho de dirigentes de pequenas e médias empresas. Revista de Administração IA-USP, v. 17, n. 2, p. 73-80, abr./jun. 1982. 